\title{
Pemanfaatan Aplikasi Android Dalam Rancang Bangun Sistem Informasi Persebaran Indekos di Wilayah Pancor Kabupaten Lombok Timur
}

\author{
Nurhidayati $1^{*}$, Amri Muliawan Nur ${ }^{2}$ \\ 1,2 Program Studi Sistem Informasi, Universitas Hamzanwadi \\ *hidayati2188@gmail.com
}

\begin{abstract}
Abstrak
Universitas Hamzanwadi merupakan salah satu perguruan Tinggi Swasta yang ada di Kota Selong, Lombok Timur Nusa Tenggara Barat. Sebagai salah satu pusat pendidikan Universitas Hamzawandi tentunya, akan selalu didatangi ribuan mahasiswa baru dari berbagai daerah setiap tahunnya. Begitu pula dengan persebaran rumah kost yang akan menjadi incaran bagi para mahasiswa-mahasiswi yang berasal dari luar wilayah Pancor Selong untuk mencari rumah kost tersebut. Rumah kost adalah salah satu tempat penyedia jasa penginapan atau tempat tinggal sementara.[1] Seringnya dijumpai ketersediaan jumah kamar kost yang tidak sebanding dengan pencari kost-kostan merupakan suatu masalah bagi kedua belah pihak (pencarikost dan pemilik). Oleh karena itu pencari kost harus mencari informasi lebih cepat agar mendapat tempat tinggal yang sesuai, baik itu dari segi kelengkapan kamar atau harga kost. Sementara pemilik kost untuk melakukan promosi masih secara manual yakni dari mulut kemulut dan biasanya menempelkan nama kost di depan gerbang kost-kostan. Dengan adanya permasalahan tersebut, maka peneliti mencoba membuat suatu sistem informasi pencarian kost - kostan berbasis android sebagai penyelesaian masalah tersebut. Sistem informasi pencarian tempat kost berbasis android ini adalah sebuah aplikasi yang dapat digunakan para pendatang dari luar wilayah Pancor - Selong yang merasa kebingungan dalam mencari rumah kost yang sesuai keinginannya, serta membantu pemilik kost dalam mempromosikan rumah kost-kostannya. Dalam perancangannya, aplikasi ini dilakukan dengan menggunakan metodelogi waterfall, di mana waterfall adalah sebuah metode pengembangan sistem yang diawali dengan tahap analisis, kemudian perancangan sistem dan implementasi pembuatan aplikasi serta mengujinya kepada pengguna. Sistem ini menggunakan bahasa pemrograman java dengan software progamming yang memanfaatkan android studio.[2].
\end{abstract}

Kata Kunci : Android, Java, Maps, Rumah Kos, Software, Sistem Informasi

\begin{abstract}
Hamzanwadi University is a private university in Selong City, East Lombok, West Nusa Tenggara. As one of the education centers for Hamzawandi University, of course, there will always be thousands of new students from various regions every year. Likewise with the distribution of boarding houses which will be the target of students who come from outside the Pancor - Selong area to look for the boarding house. A boarding house is one of the places for lodging service providers or a temporary residence. [1] Often encountered the availability of boarding rooms that are not comparable with boarding-boarding seekers is a problem for both parties (boarder and owner). Therefore boarding seekers must find information more quickly in order to get an appropriate place to live, be it in terms of room completeness or boarding price. Meanwhile, boarding house owners still do promotions manually, namely from the mouth of their mouth and usually stick the name of the boarding house in front of the boarding gate. With this problem, the researchers tried to create an android-based boarding information system to solve the problem. This android-based boarding information system is an application that can be used by newcomers from outside the Pancor - Selong area who feel confused in finding a boarding house that suits their wishes, as well as helping boarding owners in promoting their boarding houses. In its design, this application is carried out using the waterfall methodology, in which the waterfall is a system development method that begins with the
\end{abstract}


DOI : 10.29408/jit.v4i1.2989 Link : https://dx.doi.org/10.29408/jit.v4i1.2989

analysis stage, then system design and implementation of making applications and testing it to the user. This system uses the Java programming language with programming software that utilizes Android Studio. [2]

Keywords: Android, Java, Maps, Boarding House, Software, Information System

\section{Pendahuluan}

Teknologi diciptakan untuk membantu dan mempermudah pekerjaan manusia. Dimana saat ini teknologi sangat berperan besar bagi manusia untuk menyelesaikan berbagai macam persoalan. Dengan kecanggihan teknologi, keadaan ini sangat mendorong manusia untuk terus melakukan berbagai percobaan dan penelitian serta terus berinovasi guna memberikan manfaat yang lebih untuk mempermudah mendapatkan berbagai macam informasi. IImu pengetahuan dan teknologi berkembang terus bahkan saat ini berlangsung dengan sangat pesat.[3] Perkembangannya bahkan bukan hanya dalam hitungan tahun, bulan, atau hari, melainkan jam, bahkan menit atau detik terutama berkaitan dengan teknologi informasi dan komunikasi yang ditunjang dengan teknologi elektronika. Pengaruhnya meluas keberbagai bidang kehidupan, pengaruh ini sangat cepat memberikan dampak positif dan dampak negatif. Perkembangan ilmu dan teknologi berdampak positif dilihat dengan semakin terbuka dan tersebarnya informasi dan pengetahuan keseluruh dunia menembus batas ruang dan waktu. Dapak negatifnya yaitu terjadinya perubahan nilai, norma, aturan, atau moral kehidupan yang bertentangan dengan nilai, norma, aturan, dan moral kehidupan yang dianut masyarakat. Namun hal itu kembali pada pribadi kita masing-masing yaitu bagaimana cara kita menyambut atau menerima perkembangan teknologi itu sendiri.[4]

Salah satu contoh manfaat dari perkembangan teknologi adalah dalam bidang Sistem Informasi Geografis seperti persebaran indekos. Indekos atau rumah kost adalah salah satu tempat penyedia jasa penginapan atau tempat tinggal sementara yang terdiri dari beberapa kamar dan setiap kamar memiliki beberapa fasilitas serta harga yang sudah ditentukan oleh pemilik kost atau wali kost. Pemilik kost dalam hal promosi rumah kost-kostan masih menggunakan cara konvensional, yaitu hanya bertuliskan "terima kost atau terima kontrak" di depan gerbang kostkostannya. Area promosi pun hanya sekitar tempat kost itu saja sehingga bagi pendatang dari luar wilayah Pancor -Selong yang ingin menyewa akan kesulitan mengetahui informasi tersebut.[1]

Namun dalam persebaran indekos tidak jarang kita temui orang luar atau pendatang dari luar yang ingin sekolah di Pancor ataupun yang bekerja di wilayah tersebut pasti mencari tempat tinggal. Sementara mencari rumah kost itu bisa dikatakan sedikit sulit mengingat wilayah Pancor 
DOI : 10.29408/jit.v4i1.2989 Link : https://dx.doi.org/10.29408/jit.v4i1.2989

itu luas dan persebaran rumah kost pun di berbagai tempat, belum lagi terdapat tempat kost di gang-gang kecil yang tidak banyak diketahui oleh orang luar. Dan itupun kita harus melihat langsung kondisi kostnya seperti apa belum lagi tidak cocok, entah itu karna kurangnya fasilitas atau harganya yang kemahalan jadi pencari kos harus cari rumah kost yang lain lagi, dan tentu itu membutuhkan waktu dan menguras tenaga juga. Pencarian lewat google pun kurang efisien, karena untuk mencari informasi kost, harus buka link google terlebih dahulu. Saat ini untuk mendapatkan informasi tempat penyewaan yang lebih rinci dan terfokus khususnya melalui android masih sangat sulit ditemukan. Untuk mengatasi permasalahan tersebut maka dibutuhkan suatu aplikasi untuk memudahkan mereka mencari tempat tinggal tanpa harus datang dan memeriksa tempat kost satu - persatu.[5] Maka dari itu peneliti mencoba memberi solusi dengan melakukan penelitian yang berjudul "Pemanfaatan Aplikasi Android Dalam Rancang Bangun Sistem Informasi Persebaran Indekos Di Wilayah Pancor Kabupaten Lombok Timur". Dengan harapan sistem ini bisa membantu permasalaahan kedua belah pihak, dalam hal ini pencari dan pemilik kost.

\section{Tinjauan Pustaka}

\subsection{Penelitian Terkait}

Dalam penelitian ini, penulis terinspirasi menggunakan referensi dari penelitian-penelitian sebelumnya, yang terkait penggunaan Android Studio dengan memanfaatkan Google Maps API. Adapun beberapa penelitian terkait sebagai berikut :

- Penelitian yang dilakukan (Sudianto A., Nurhidayati, \& Wijaya, L. K., 2020) tentang "Penerapan Sistem Informasi Geografis Untuk Pemetaan Bengkel Tambal Ban di Kecamatan Selong Kabupaten Lombok Timur". Hasil dari penelitian ini untuk memajukan para pelaku usaha kecil menengah terutama dari segi informasi lokasi seperti halnya usaha bengkel tambal ban yang sangat butuh sentuhan teknlologi agar keberadaan usaha tersebut lebih diketahui oleh masyarakat luas. Jumlah bengkel tambal ban yang begitu banyak tersebar di kecamatan selong membuat usaha ini perlu mendapat perhatian lebih, mengingat jenis usaha ini memiliki peran yang sangat penting dalam kelancaran transportasi masyarakat. Berdasarkan permasalahan tersebut penulis mengangkat tema penelitian Penerapan Sistem Informasi Geografis Untuk Pemetaan Bengkel Tambal Ban Di Kecamatan Selong Kabupaten Lombok Timur.[6] 
DOI : 10.29408/jit.v4i1.2989 Link : https://dx.doi.org/10.29408/jit.v4i1.2989

- Penelitian yang dilakukan (Wasil. M., Samsu, L. M., \& Putra, Y. K, 2020) tentang "Sistem Informasi Geografis Untuk Pemetaan Homestay di Lombok Timur Berbasis Android". Sistem informasi geografis pemetaan homestay di Lombok Timur dibuat sebagai media penyebaran informasi dalam penyampaian informasi homestay bagi wisatawan yang akan berkunjung ke Lombok khususnya di Lombok Timur. Sistem informasi berbasis android ini menyajikan gambar, deskripsi dan juga lokasi yang ditampilkan melalui google maps sebagai petunjuk arah menuju lokasi homestay berdasarkan pilihan dari masing-masing kategori homestay. Sistem informasi tersebut dapat digunakan sekaligus menunjang sektor pariwisata di Lombok dan memudahkan wisatawan untuk mendapatkan informasi yang lengkap dan efektif. Sistem informasi geografis pemetaan homestay di Lombok Timur berbasis Android dibuat dengan program Android Studio dan Google Maps sebagai panduan lokasi wisata. Dapat disimpulkan bahwa sistem ini siap untuk dikembangkan.[7]

- Penelitian yang dilakukan (Muliwan Nur, A. Mahfuz, 2020) tentang "Pemetaan Rumah Makan Lesehan Di Kecamatan Selong Dan Masbagik Kabupaten Lombok Timur Berbasis Gis (Geographic Information
System)". Dari hasil penelitian ini, dapat diambil kesimpulan bahwa telah dihasilkan suatu "Sistem Informasi Geografis Berbasis Web Untuk Pemetaan Rumah Makan Lesehan Di Kecamatan Selong Dan Masbagik Kabupaten Lombok Timur", yang dapat membantu menginformasikan masyarakat secara efektif dan efisien. Dari sistem gis yang dibuat terdapat fitur-fitur yang dapat memudahkan masyarakat untuk mengetahui posisi rumah makan lesehan, informasi rumah makan lesehan, posisi rumah makan lesehan, serta petunjuk arah menuju rumah makan lesehan sehingga masyarakat dapat memilih opsi rumah makan lesehan sesuai dengan selera dan keinginan.[8]

Penelitian yang dilakukan (Sudianto, Aris;. Sadali, Muhamad, 2018) tentang "Penerapan Sistem Informasi Geografis (GIS) dalam Pemetaan Kerajinan Kain Tenun dan Gerabah untuk Meningkatkan Potensi Kerajinan di Kabupaten Lombok Timur". Dengan dibangunnya aplikasi sistem informasi geografis untuk pemetaan lokasi kerajinan kain tenun dan gerabah dii kabupaten lombok timur, diharapkan dapat membantu dalam meningkatkan potensi kerajinan yang ada di kabupaten lombok timur khususnya kerajinan kain tenun dan gerabah menjadi lebih baik lagi. Sehingga 
DOI : 10.29408/jit.v4i1.2989 Link : https://dx.doi.org/10.29408/jit.v4i1.2989

dapat membuat kerajinan kain tenun dan gerabah dapat kembali bersaing dengan kerajinan lain yang tersebar di daerah daerah lain.[9]

- Penelitian yang dilakukan oleh Rifan Hananto, dkk yang berjudul "Sistem Informasi Penyewaan Kamar Kos Qoi di Purwakarta". Dalam pembuatan Sistem Informasi Penyewaan Kamar Kost Qoi Purwakarta ini, pencatat memakai desain pembangunan metode prototype. Hasilnya ialah sistem informasi penyewaan kamar kost yang dapat memberikan informasi yang dapat memfasilitasi pencari kost untuk mendapatkan informasi kamar kost yang sesuai dengan kriteria dan melakukan pemesanan tanpa harus datang ke lokasi langsung, pemilik kost dapat mengelola apapun yang bersangkutan dengan tempat kost tersebut pada sebuah sistem informasi berbasis website secara mudah.[10]

\subsection{Landasan Teori}

Pengertian Sistem, Informasi, dan Sistem Informasi

\section{Sistem}

Menurut Poerwadarminta mendefinisikan sistem bahwa, "Sistem yakni merupakan sekelompok bagian yang berupa alat \& lain sebagainya, yang mana sekelompok tersebut bekerja sama untuk mencapai tujuan tertentu".[11]

\section{Informasi}

Menurut George R. Terry berpendapat bahwa "Informasi adalah data yang penting yang memberikan pengetahuan yang berguna".

\section{Sistem Informasi}

Menurut Sutarman Robert A. Leitch dan K. Roscoe Davis (2005: 11), "Sistem Informasi adalah suatu sistem di dalam suatu organisasi yang mempertemukan kebutuhan pengolahan transaksi harian, mendukung operasi, bersifat manajerial dan kegiatan strategi dari suatu organisasi dan menyediakan pihak luar tertentu dengan laporan-laporan yang diperlukan".

4. Indekos (Rumah Kost)

Indekos atau rumah kost adalah sebuah jasa yang menawarkan sebuah kamar atau tempat untuk ditinggali sementara dengan sejumlah pembayaran tertentu untuk setiap periode tertentu juga. Kata ini diserap dari frasa bahasa Belanda "in de kost". Definisi "in de kost" sebenarnya adalah "makan di dalam", tetapi dapat pula berarti "tinggal dan makan" di dalam rumah tempat menumpang tinggal. Pada zaman kolonial Belanda di Indonesia, "in de kost" adalah sebuah gaya hidup yang cukup populer di kalangan menengah ke atas untuk kaum pribumi, terutama sebagian kalangan yang mengagungagungkan budaya barat atau Eropa khususnya adat Belanda, dengan trend ini mereka berharap banyak agar anaknya dapat bersikap dan 
DOI : 10.29408/jit.v4i1.2989 Link : https://dx.doi.org/10.29408/jit.v4i1.2989

berprilaku layaknya bangsa Belanda atau Eropa yang dirasa lebih terhormat saat itu.

5. Android

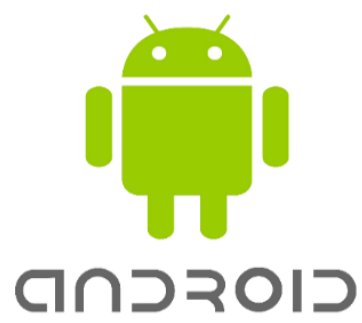

Gambar 1. Android

Android adalah sebuah sistem operasi untuk perangkat mobile berbasis linux yang mencangkup sistem operasi, middleware, dan aplikasi. Android menyediakan platform yang terbuka bagi para pengembang untuk menciptakan aplikasi mereka. Awalnya, Google Inc. membeli Android Inc. yang merupakan pendatang baru yang membuat peranti lunak untuk ponsel / smartphone. Android merupakan generasi baru platform mobile yang memberikan pengembangan untuk melakukan pengembangan sesuai dengan yang diharapkannya. Sistem operasi yang mendasari Android dilisensikan dibawah GNU, General Public Lisensi versi 2 (GPLv2), yang sering dikenal dengan istilah "copyleft" lisensi dimana setiap perbaikan pihak ketiga harus terus jatuh dibawah terms. Android didistribusikan di bawah lisensi Apache Software (ASL/Apache2), yang memungkinkan untuk distribusi kedua dan seterusnya.
6. Android Studio

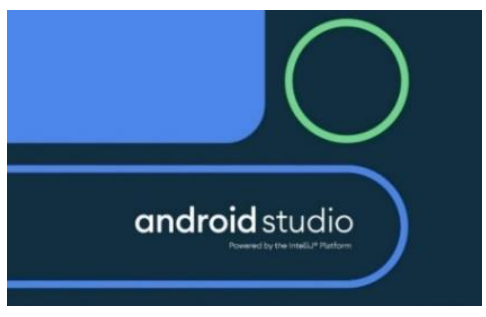

Gambar 2. Android Studio

Android Studio adalah lingkungan pengembangan baru dan terintegrasi penuh, yang baru saja dirilis oleh Google untuk sistem operasi Android. Android Studio dirancang untuk menjadi peralatan baru dalam pengembangan aplikasi dan juga memberi alternatif lain selain Eclipse yang saat ini menjadi IDE yang paling banyak digunakan. Saat Anda memulai proyek baru dengan Android Studio, struktur proyek akan muncul bersama dengan hampir semua berkas yang ada di dalam direktori SDK, peralihan ke sistem manajemen berbasis Gradle ini memberikan fleksibilitas yang lebih besar pada proses pembangunanya. Android Studio mengijinkan anda untuk melihat perubahan visual apapun yang anda lakukan pada aplikasi secara langsung. Anda juga bisa melihat perbedaannya jika dipasang pada beberapa perangkat Android yang berbeda, termasuk konfigurasi dan resolusinya secara bersamaan.

7. Java 


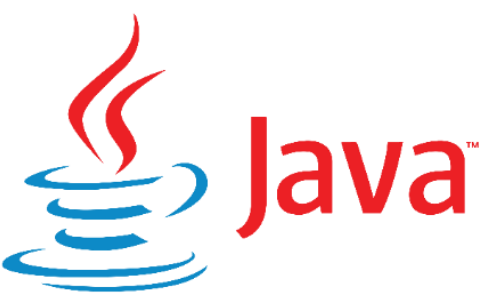

Gambar 3. Java

Java adalah sebuah bahasa pemrograman, java dapat membuat seluruh bentuk aplikasi, desktop, web, dan lainnya, sebagaimana dibuat dengan menggunakan bahasa pemrograman konvensional yang lain. Java adalah bahasa pemrograman yang berorentasi objek (OOP) dan dapat dijalankan pada berbagai platform sistem operasi. Perkembangan java tidak hanya terfokus pada satu sistem operasi, tetapi dikembangkan untuk berbagai sistem operasi yang bersifat open source.[12]

\section{Database}

Database atau basis data adalah kumpulan informasi yang disimpan di dalam komputer secara sistematik sehingga dapat diperiksa menggunakan suatu program komputer untuk memperoleh informasi dari basis data tersebut. Perangkat lunak yang digunakan untuk mengelola dan memanggil kueri (query) basis data disebut sistem manajemen basis data. Sistem basis data dipelajari dalam inlmu informasi.

9. Firebase

\section{Firebase}

Firebase merupakan layanan database yang dimiliki google yang dapat mempermudah pekerjaan Mobile Apps Developer. Maka dari itu tidak aneh jika sekarang firebase banyak digunakan, karena memang banyak fitur menarik yang disediakan.

\section{Google Maps API}

Google Maps API adalah suatu library berbentuk JavaScript. Cara membuat Google Map untuk ditampilkan pada suatu web atau blog sangat mudah hanya dengan membutuhkan pengetahuan mengenai HTML serta JavaScript, serta koneksi internet yang stabil. Dengan menggunakan Google Map API kita dapat menghemat waktu dan biaya untuk membangun aplikasi peta digital yang handal, sehingga kita dapat fokus hanya pada data-data yang akan ditampilkan.

11. Sistem Informasi Geografis (SIG)

Geographical Information System (GIS) yang dalam bahasa indonesia dikenal sebagai Sistem Informasi Geografis (SIG) didefinisikan sebagai sebuah sistem informasi yang digunakan untuk memasukan, menyimpan, mengambil, memanipulasi, menganalisa, dan menghasilkan data geopasial atau data yang mengacu secara 
DOI : 10.29408/jit.v4i1.2989 Link : https://dx.doi.org/10.29408/jit.v4i1.2989

geografis. GIS digunakan dalam rangka mendukung pengambilan keputusan untuk perencanaan dan pengelolaan dari penggunaan lahan, sumber daya alam, lingkungan, transportasi, fasilitas perkotaan, dan rekan administrasi lainnya.

\section{Pengertian Flowchart}

Flowchart adalah penyajian yang sistematis tentang proses dan logika dari kegiatan penanganan informasi atau penggambaran secara grafik dari langkah-langkah dan uruturutan prosedur dari suatu program. Flowchart menolong analis dan programmer untuk memecahkan masalah kedalam segmen-segmen yang lebih kecil dan menolong dalam menganalisis alternatif-alternatif lain dalam pengoperasian.

\subsection{Tahapan Penilitian}

Adapun tahap - tahap yang dilakukan dalam penelitian ini ditunjukkan dalam bentuk flowchart, Berikut ini merupakan rancangan flowchart untuk menunjukan aliran kerja sistem atau untuk menggambarkan aliran kejadian sistem kerja yang diusulkan.

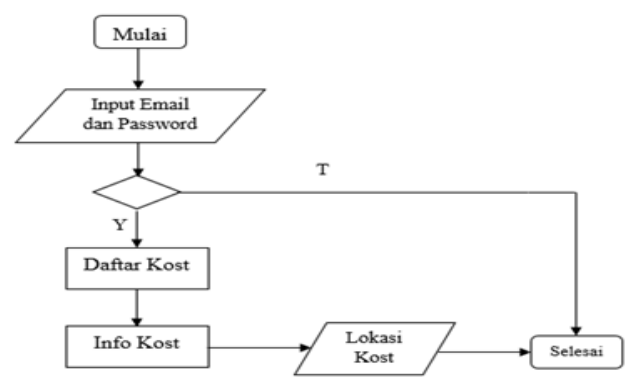

Gambar 5. Flowchart Pencarian Kost.

\section{Metode Penelitian}

Dalam tahap ini, ada beberapa kegiatan yang harus dilaksanakan dengan baik. Adapun tahapan kegiatan dalam pelaksanaan penelitian ini antara lain terdiri dari :

\subsection{Pengumpulan Data}

Kegiatan ini harus didasarkan pada pedoman yang sudah dipersiapkan dalam rancangan penelitian. Data yang dikumpulkan melalui kegiatan penelitian dijadikan dasar dalam menguji hipotesis yang diajukan. Adapun data yang digunakan dalam penelitian ini diambil dari pe,lik kost yang ada diwilayah pancor Lombok Timur.

\subsection{Analisis Data}

Pengolahan data atau analisis ini dilakukan setelah data terkumpul semua yang kemudian dianalisis, dan dihipotesis yang diajukan diuji kebenarannya melalui analisis tersebut. Jika jenis data yang dikumpulkan itu berupa data kualitatif, maka pengolahan datanya dilakukan dengan cara menarik kesimpulan deduktifinduktif, namun jika data yang dikumpulkan berupa jenis data kuantitatif atau berbentuk angka-angka, maka analisis yang digunakan menggunakan analisis kuantitatif atau statistika sebelum menarik kesimpulan secara kualitatif.

\subsection{Lokasi Penelitian}

Lokasi penelitian merupakan tempat, dan kegiatan yang dapat di observasi. Adapun yang 
DOI : 10.29408/jit.v4i1.2989 Link : https://dx.doi.org/10.29408/jit.v4i1.2989

menjadi lokasi dalam penelitian ini adalah rumah kos - kosan yang berada di wilayah sekitaran Pancor - Selong Kabupaten Lombok Timur.

\section{Hasil dan Pembahasan}

Berdasarkan hasil analisis sistem, penerapan teknologi pada aplikasi pencarian indekos ini adalah dalam mencari lokasi. Pada saat awal aplikasi dijalankan sistem akan menampilakan halaman utama dan pengguna hanya tinggal menekan tombol pencarian indekos kemudian sistem akan menampilkan daftar indekos yang sudah terdaftar pada aplikasi.[13] Selanjutnya pengguna tingal melihat daftar indekos yang ada dan menuju ke map jika sudah memilih indekos yang akan dituju.

\subsection{Tampilan Interface}

\section{Form Awal}

Pada tampilan awal aplikasi pencarian rumah kost ini akan menampilkan selamat datang dan pada bagian paling bawah terdapat tombol yang dapat ditekan untuk login.

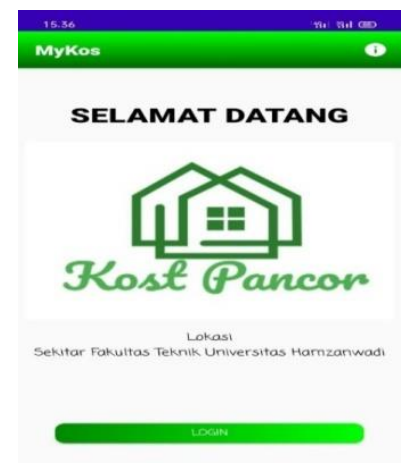

Gambar 6. Form Awal

\section{Form Login}

Untuk memulai aplikasi anda dianjurkan untuk login terlebih dahulu.

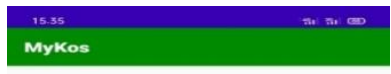

\section{LOG IN}

Gambar 7. Form Login

\section{Form Daftar Kost}

Pada tampilan daftar kost aplikasi ini akan menampilkan berupa gambar, nama kost, dan harga kost. Pada daftar gambar dapat ditekan untuk melihat lebih detail tentang kost yang dipilih.

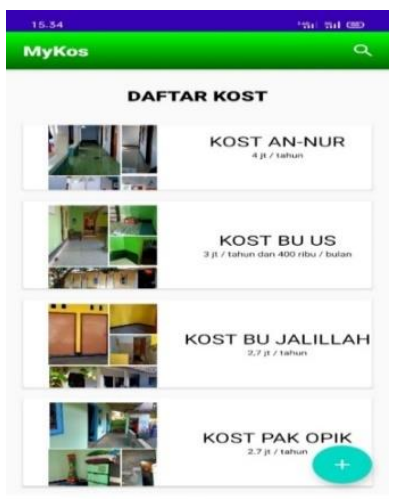

Gambar 8. Form Daftar Kost

4. Form Info Kost

Pada tampilan informasi kost akan ditampilkan gambar kost beserta penjelasan tentang nama kost, harga kost, fasilitas, jenis kost, jumlah kamar, alamat kost, dan nomor kontak pemilik kost. Dan pada bagian bawah kost terdapat 
DOI : 10.29408/jit.v4i1.2989 Link : https://dx.doi.org/10.29408/jit.v4i1.2989

tombol yang dapat ditekan untuk menuju ke Google Maps.

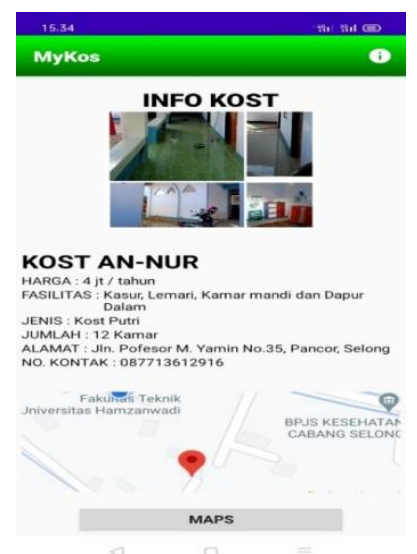

Gambar 9. Form Info Kost

\section{Form Google Maps}

Pada tampilan Google Maps akan langsung mengarahkan pencari kost ke lokasi kost yang sudah dipilih.

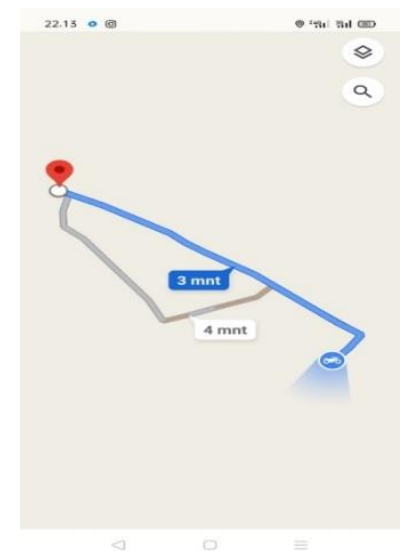

Gambar 10. Googlr Maps

\subsection{Pengujian Sistem}

Tahap pengujian dilakukan dengan menggunakan metode black box yang artinya suatu pengujian yang berfokus pada fungsional perangkat lunak tanpa memperdulikan source code program. Pengujian ini dilakukan dalam sepuluh kali percobaan, pengujian dilakukan pada aplikasi pencarian indekos dengan target keberhasilannya adalah munculnya peta atau Google Maps. [14]

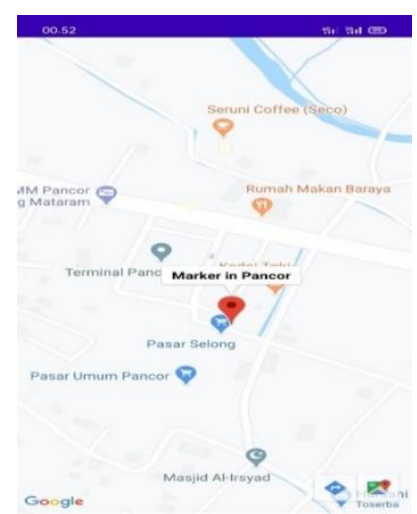

Gambar 11. Hasil Uji Coba Google Maps Tabel 1. Uji Coba

\begin{tabular}{|c|l|l|}
\hline Uji Ke- & Hasil & Status \\
\hline 1. & Google Maps Muncul & Berhasil \\
\hline 2. & Google Maps Muncul & Berhasil \\
\hline 3. & Google Maps Muncul & Berhasil \\
\hline 4. & Google Maps Muncul & Berhasil \\
\hline 5. & Google Maps Muncul & Berhasil \\
\hline 6. & Google Maps Muncul & Berhasil \\
\hline 7. & Google Maps Muncul & Berhasil \\
\hline 8. & Google Maps Muncul & Berhasil \\
\hline 9. & Google Maps Muncul & Berhasil \\
\hline 10. & Google Maps Muncul & Berhasil \\
\hline
\end{tabular}

\section{Kesimpulan}

Berdasarkan dari hasil uji coba dan analisis yang peneliti lakukan maka dapat ditarik kesimpulan bahwa : 
1. Aplikasi persebaran indekos di wilayah Pancor - Selong adalah aplikasi berbasis Android, yang dapat memetakan dan mencari Persebaran lokasi rumah kost.

2. Telah dilakukan uji fungsional dan black box pada aplikasi yang menunjukan bahwa aplikasi sudah berjalan dengan baik.

3. Proses pencarian indekos menjadi lebih mudah, sehingga efisiensi waktu, tenaga, dan materi dapat diatasi dengan mudah.

4. Aplikasi dapat memberikan informasi lokasi indekos kepada pengguna.

5. Aplikasi yang dibangun memiliki manfaat yang sangat baik dan juga dinilai memudahkan masyarakat dalam pencarian rumah kost.

6. Memberikan dampak positif bagi kedua belah pihak (pemilik dan pencari kost).

\section{Daftar Pustaka}

[1] F. A. Sugeng Santoso, llamsyah, "Aplikasi Monitoring Rumah Kos Berbasis Android," J. Maklumatika, vol. 5, no. 2, pp. 129-139, 2019, [Online]. Available: http://maklumatika.uniat.ac.id/files/vol5no 2januari2019/002.pdf.

[2] E. M. Pratiwi et al., "SEKITAR AKADEMI TELKOM JAKARTA BERBASIS," pp. 114.

[3] S. Multidisiplin and I. Pengetahuan, "Prosiding Seminar Nasional 2019 PESONA : SISTEM INFORMASI PEMESANAN SALON ONLINE Seminar Nasional Sinergitas Multidisiplin IImu Pengetahuan dan Teknologi ( SMIPT ),
Prosiding Seminar Nasional 2019

Seminar Nasional Sinergitas Multidisiplin Ilmu Pengetahuan," vol. 2, no. 2011, pp. 1-7, 2019.

[4] U. Rahmalisa and Herianto, "Perancangan Aplikasi Rumah Kos Berbasis Web Wilayah Pekanbaru," J. IImu Komput., vol. 9, no. 1, pp. 1-6, 2020, doi: 10.33060/jik/2020/vol9.iss1.154.

[5] R. Manurung, S. Tinggi, I. Komputer, and Y. Sudarso, "Efektifitas pencarian kost dengan sistem informasi berbasis android," vol. 6, no. 2, 2020.

[6] A. Sudianto, Nurhidayati, and L. K. Wijaya, "Penerapan Sistem Informasi Geografis Untuk Pemetaan Bengkel Tambal Ban di Kecamatan Selong Kabupaten Lombok Timur," Infotek: Jurnal Informatika dan Teknologi, vol. 3, no. 1. pp. 51-57, 2020, doi: 10.1128/EC.00411-07.

[7] M. Wasil, L. M. Samsu, and Y. K. Putra, "Sistem Informasi Geografis Untuk Pemetaan Homestay di Lombok Timur Berbasis Android," Jurnal Informatika dan Teknologi, vol. 3, no. 1. pp. 5-9, 2020, doi: 10.1029/2019GH000237.

[8] A. M. Muliwan Nur, "Pemetaan Rumah Makan Lesehan Di Kecamatan Selong Dan Masbagik Kabupaten Lombok Timur Berbasis Gis (Geographic Information System)," vol. 3, no. 1, pp. 8-14, 2020.

[9] S. Sudianto, Aris; Muhamad, "Penerapan Sistem Informasi Geografis (GIS) dalam Pemetaan Kerajinan Kain Tenun dan Gerabah untuk Meningkatkan Potensi Kerajinan di Kabupaten Lombok Timur," vol. 1, no. 2, 2018.

[10] R. H. Solikhin, R. P. Dhaniawaty, and M. Kom, "Rent Information System of Kost Room Qoi Purwakarta," p. 7. 
DOI : 10.29408/jit.v4i1.2989 Link : https://dx.doi.org/10.29408/jit.v4i1.2989

[11] T. Informatika et al., "Aplikasi manajemen kost pada kost kembar."

[12] K. Q. Fredlina et al., "Model Sistem Informasi Pura Kawitan Berbasis Android ( Studi Kasus di Provinsi Bali )," pp. 127138.

[13] P. Studi, S. Informasi, F. Sains, and U. I. N. S. Riau, "Rancang Bangun Aplikasi Pencarian Rute Kos-Kosan," vol. 6, no. 1, pp. 16-25, 2020.

[14] N. L. Hasanah, "Rumah Kost Berbasis Web," vol. 8, no. 2, pp. 78-86, 2020. 